\title{
A Stable DC Power Supply for Photovoltaic Systems
}

\author{
Hussain A. Attia*, Beza Negash Getu, and Nasser A. Hamad \\ Department of Electrical, Electronics and Communications Engineering, American University of Ras Al Khaimah, \\ Ras Al Khaimah, UAE
}

\begin{abstract}
The use of solar energy as source of power is becoming not a choice but a necessity due to the unprecedented growth in the demand and consumption of electrical power for various applications. The solar power from the Photovoltaic (PV) systems is currently used as a standalone PV system or integrated with the electric grid. However, the generated DC power from PV systems is not stable due to weather, atmospheric and environmental conditions, which requires the design of a DC power supply to produce a stable and regulated DC voltage output. In this paper, a new design of power supply is presented that provides a stable output voltage $($ Vout $=+12 \mathrm{~V}, 0 \mathrm{~V},-12 \mathrm{~V})$ over significant range of input voltage variations ( $\mathrm{Vin}=+15 \mathrm{~V}$ to $+50 \mathrm{~V}$ ) emulating the variation of output voltage of $\mathrm{PV}$ systems. The stabilization of the output voltage reflects the effectiveness of the proposed design for photovoltaic systems applications. The system is simulated using NI-MULTISIM software. A satisfactory simulation result is obtained showing a strong promise to practically implement using discrete components.
\end{abstract}

Keywords: PV System, Voltage Variation, Sensing \& Protection Circuit, Op-Amp, Zener Diode, DC Supply

\section{Introduction}

The high rate of growth in electronic devices and equipment paralleled with the growing rate of their use for communications, transportations, medical services, educational purposes, modern agricultural practices, control systems and various home services demands the need for sustainable, affordable and uninterrupted power supply for the proper functioning of the devices at any state of time and locations. The conventional non-renewable energy or power sources (fossil fuels, nuclear fuels) are getting depleted from time to time due to the increase in high consumption rate and hence the trend is to use renewable energy sources (solar, wind) as an alternative energy is becoming an obligation and not a simple choice. Renewable energy sources are also environmentally friendly green sources of energy while fossil fuels create pollution and global warming problems in the long term [1].

\begin{abstract}
Among the renewable sources, solar power is significantly contributing to electricity generation since it is abundant, widespread available and especially its usefulness to be used in remote and rural locations. Solar energy is converted into electricity through photovoltaic (PV) systems or solar cells to be used for various applications [1] - [4]. Many individual solar cells are collected and arranged to form large flat panels to maximize the power output from solar energy. The level of solar energy absorption can be further enhanced by adjusting the surface of the solar panel in the direction of sun light during full day timing. In [5], [6], the Authors designed and presented an electronic system for single axis and dual-axis tracking of the solar sun. The electronic system consists of a set of sensors located on the solar panel which are responsible for sensing and indicating the maximum solar energy direction and thus the system moves the panel in the horizontal or vertical plane towards maximum solar energy absorption.

Photovoltaic cells generate direct current (DC) that can be used for small electrical or electronic appliances and in this case, it is a standalone system working as a sole source of power.
\end{abstract}

*Corresponding Author

E-mail: hattia@aurak.ae

(C) 2016 International Association for Sharing Knowledge and Sustainability

DOI: $10.5383 /$ ijtee.12.01.009 
The DC from photovoltaic cell need to be changed to AC using inverters for AC applications or when solar power is integrated with electric grid as additional source of electricity for commercial applications like in electric utilities [7], [8]. The instantaneous levels of output DC voltage of solar panels suffer from the fluctuation between low and high levels according to the instantaneous values of the solar radiation due to the change in weather conditions. The maximum power points (MPPs) of photovoltaic modules change with both outer atmospheric conditions and the temperature of cells. This is especially critical when the solar array or panel is working as standalone configuration where it can't be reliable in providing a well-regulated load voltage [7]-[12].Therefore a regulated DC-DC converter is a strong requirement to obtain a stable voltage from solar panels. A PV system with regulated DC-DC converter supplying a rechargeable battery is a suitable choice for a standalone PV system. In this paper, a stable and regulated DC supply is designed for PV applications. The proposed DC power supply is designed to work with solar power input voltage in the range of $(\mathrm{Vin}=+15 \mathrm{~V}$ to $+50 \mathrm{~V})$. The system manipulates the low voltage levels or the voltage fluctuations that may occur in the case of low solar radiation, and produces an output voltages (Vout $=+12 \mathrm{~V}, 0 \mathrm{~V},-12 \mathrm{~V})$. A power cut protection part is added to the power supply circuit to cut off the solar panel when the solar panel voltage is less than the limited lower level. The NI MULTISM simulation software for electronic circuits design is used to simulate all the stages. The simulation results at different stages reflect the effectiveness of the proposed electronic design.

\section{Proposed Design}

The proposed work focuses on eliminating the fluctuation demerit in the DC output voltage level of connected solar panel. The work in [7] includes the initial block diagram of the present work and [13], [14] presented a system design for portable charger used with solar power supply. In this paper, the design and simulation process takes into account the specifications of the selected solar panel type photovoltaic module 4200J with short circuit current 5.3A, open circuit voltage $45.3 \mathrm{~V}$, nominal voltage $24 \mathrm{~V}$, and the voltage $38 \mathrm{~V}$ at Maximum Power Point (MPP) of 200W.

Any photovoltaic system is expected to deliver the required DC power supply to all electronic circuits, which are included in the system. The presented paper focuses on designing a special supply to cover the full voltage range of the selected panel type according to all probability weather variations. The input voltage range to the designed DC supply is (Vin $=0 \mathrm{~V}$ to $+50 \mathrm{~V}$ ) to produce fixed output voltages (Vout $=+12 \mathrm{~V}, 0 \mathrm{~V}$, $-12 \mathrm{~V})$. On the other hand, the design offers a protection part, which is added in order to control the connection of output voltages in case the PV panel output is less than the adjusted minimum limit. The DC power supply produces a fixed DC voltage level to deliver all electronic circuits. An unregulated DC supply such as solar panel or any other DC supply is used to feed the regulated power supply that in turn delivers power to the components of the PV system without the need of battery. Fig. 1 shows the block diagram of the proposed design for the DC power supply suitable to the PV system applications.

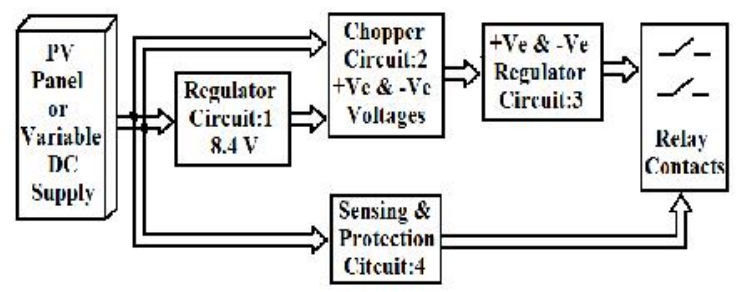

Fig. 1: Block Diagram of the Proposed DC Supply

The designed system includes four blocks, namely; regulator circuit, chopper circuit, $+\mathrm{Ve} \&-\mathrm{Ve}$ regulator circuit, and sensing \& protection circuit. The First circuit represented by first block receives the variable DC voltage from PV panels or from variable power supply under voltage range (0V to $50 \mathrm{~V})$ and produces a regulated DC output voltage of $8.4 \mathrm{~V}$. The regulated voltage $8.4 \mathrm{~V}$ is used as $\mathrm{Vcc}$ to the oscillator part in the second circuit. The second circuit represents a chopper circuit which is supplied by two voltage levels: Vcc fixed supply voltage and DC variable voltage as shown in Fig.1. The chopper circuit is designed to produce two voltage levels; one is positive while other one is negative, and these values are close to the instantaneous voltage levels of the PV panel or the variable input voltage. The third block includes two symmetric voltage regulators one for positive value and other one for negative value. The output voltage levels of the third circuit are $+12 \mathrm{~V},-12 \mathrm{~V}$ as well as $0 \mathrm{~V}$ level, which serves as a common line between positive and negative lines. The forth block includes a sensing and protection circuit that is used to control the connection state of the relay contacts. The controlling function starts by sensing the instantaneous input voltage, which is the output voltage of solar panel. The sensing part produces a low level DC voltage proportional to the actual voltage of the panel then compares it with the lower acceptable limit. The relay will be in off state in case the input voltage level is lower than the minimum limit and this will lead to disconnection of the solar panel voltage supply from the PV system.

\section{Simulation Results}

The simulation results are recorded for a range of voltage variations depending upon the selected solar panel specifications. All the blocks in the proposed design block diagram are simulated and the details of the circuit responses are collected.

\section{First Regulator Circuit}

This circuit receives variable DC voltage levels from variable DC power supply that emulates the instantaneous output voltage variation of the PV panels. The circuit produces a fixed DC voltage around $8.4 \mathrm{~V}$ because of the selected zener diode break down voltage $V_{z}=9.1 \mathrm{~V}$ through the input voltage variations approximately in the range from $10 \mathrm{~V}$ to $50 \mathrm{~V}$. Fig. 2 shows the circuit diagram and Fig. 3 the simulation voltage results of this circuit when the input voltage is varied from $0 \mathrm{~V}$ to $50 \mathrm{~V}$. 


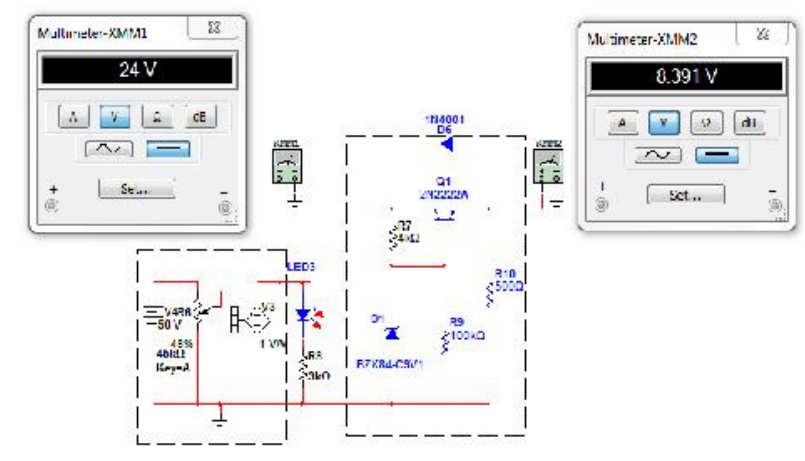

Fig. 2: Electronic Design of First Regulator Circuit

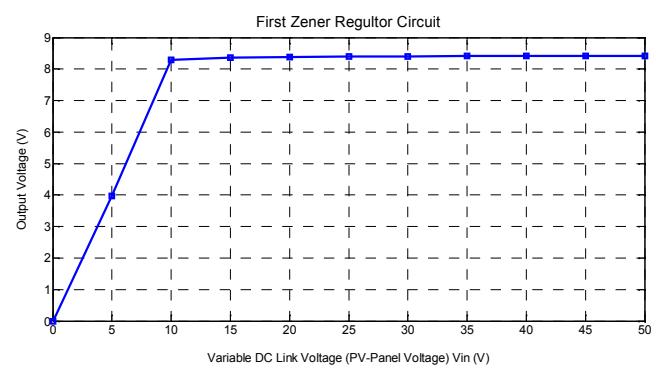

Fig. 3: The $1^{\text {st }}$ Regulator Circuit Response

\section{Chopper Circuit}

The function of the second circuit is to produce positive and negative voltage levels having a magnitude approximately equal to the input variable DC supply voltage. The proposed circuit includes two sub-circuits, namely; oscillator circuit and transformer with rectifying circuit. The oscillator circuit is constructed from a 555 timer integrated circuit, which is supplied by the output voltage of the first regulator circuit $(8.4 \mathrm{~V})$. The oscillator produces $50 \mathrm{~Hz}$ square wave for oscillating the input variable DC supply on the primary terminals of the transformer. The selected voltage transformation ratio of the transformer is 1:1.1 to have little increment in the secondary terminals of the transformer. Two rectifiers are used on the terminals of the secondary transformer to have positive and negative voltages. Fig. 4 shows the second circuit of chopper supplied by the first regulator circuit as well as the simulation results when the input voltage of the DC variable supply equals approximately $24.16 \mathrm{~V}$, Fig. 5 shows the oscilloscope channels plots channel_A shows the oscillator output while channel_B shows the output voltage difference between the positive and negative terminal. Fig. 6 shows the values of voltage levels individually. Fig. 7 shows the chopper circuit response through a wide range of input variable DC supply.

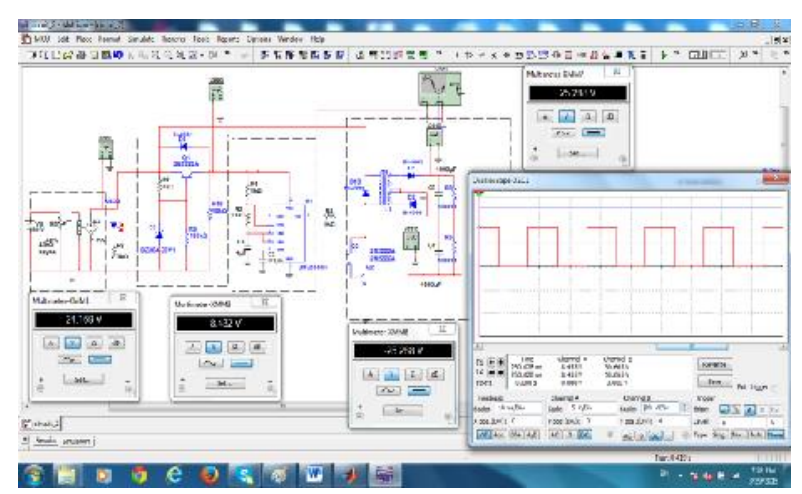

Fig. 4: Chopper Circuit Supplied by Regulator Circuit at DC Variable Supply Equals 24.16V

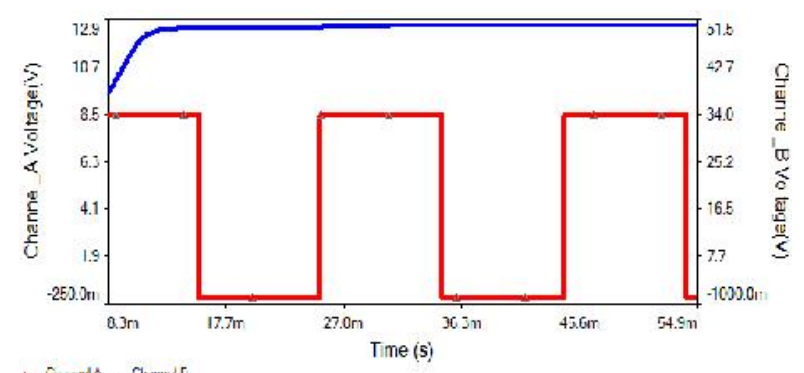

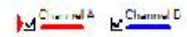

Fig. 5: Chopper Circuit Oscilloscope Output; Channel A shows the oscillator output. Channel B shows the output voltage difference between the positive and negative terminal.

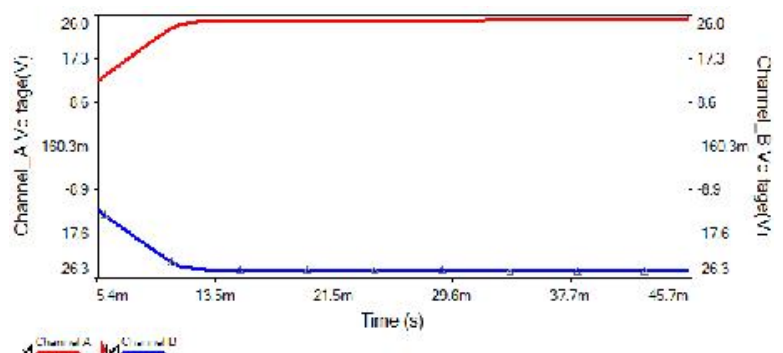

Fig. 6: Output Voltage Levels Individually of the Rectifier's Part

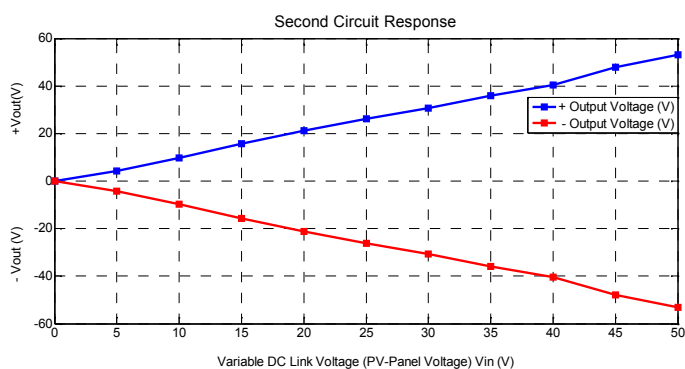

Fig. 7: Chopper Circuit Response through a Wide Range of Input Variable DC Supply 0V to 50V 


\section{Second Regulator Circuit}

This circuit receives the positive and negative voltages from the previous chopper circuit to manipulate it. The manipulation process leads to produce two fixed DC voltage levels $+12 \mathrm{~V}$, and $-12 \mathrm{~V}$. This circuit includes two parts (upper and lower as shown in Fig. 8), each part includes two regulators to produce two regulated voltage levels, which shows the simulation results when the two inputs are $+24 \mathrm{~V}$, and $-24 \mathrm{~V}$. Table I shows all collected records, which cover a wide input DC voltage variations form $0 \mathrm{~V}$ to $50 \mathrm{~V}$. Fig. 9 shows the recorded data as a graph of response for this circuit.

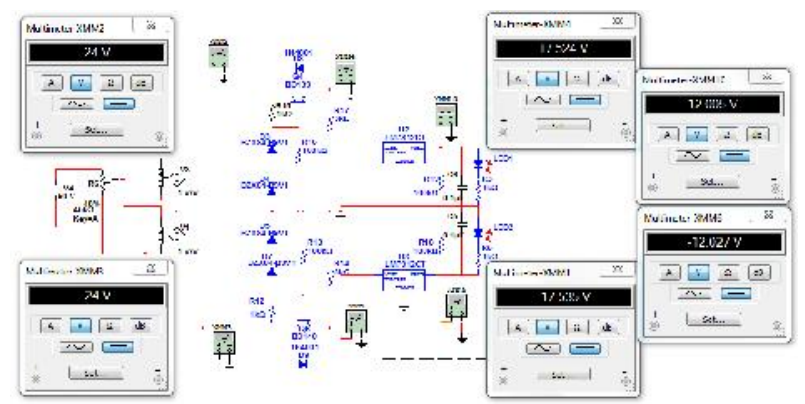

Fig. 8: Simulation Results of the Second Regulator Circuit

TABLE I: Collected Records of the 2nd Regulator Circuit at Input Voltage Range 0V to 50V

\begin{tabular}{|c|c|c|c|c|c|}
\hline $\begin{array}{c}+ \text { Vin } \\
(\mathbf{V})\end{array}$ & $\begin{array}{c}+\mathbf{V o 1} \\
(\mathbf{V})\end{array}$ & $\begin{array}{c}+\mathbf{V o 2} \\
(\mathbf{V})\end{array}$ & $\begin{array}{c}-\mathbf{V i n} \\
(\mathbf{V})\end{array}$ & $-\mathbf{V o 1}(\mathbf{V})$ & $-\mathbf{V o 2}(\mathbf{V})$ \\
\hline 0 & 0 & 0 & 0 & 0 & 0 \\
\hline 5 & 5.89 & 6.2 & -5 & -5.97 & -7.2 \\
\hline 10 & 10.8 & 10.45 & -10 & -10.8 & -10.6 \\
\hline 15 & 14.04 & 12 & -15 & -14.1 & -12 \\
\hline 20 & 17.46 & 12 & -20 & -17.46 & -12 \\
\hline 25 & 17.53 & 12 & -25 & -17.55 & -12 \\
\hline 30 & 17.57 & 12 & -30 & -17.58 & -12 \\
\hline 35 & 17.59 & 12 & -35 & -17.61 & -12 \\
\hline 40 & 17.61 & 12 & -40 & -17.63 & -12 \\
\hline 45 & 17.62 & 12 & -45 & -17.65 & -12 \\
\hline 50 & 17.64 & 12 & -50 & -17.66 & -12 \\
\hline
\end{tabular}

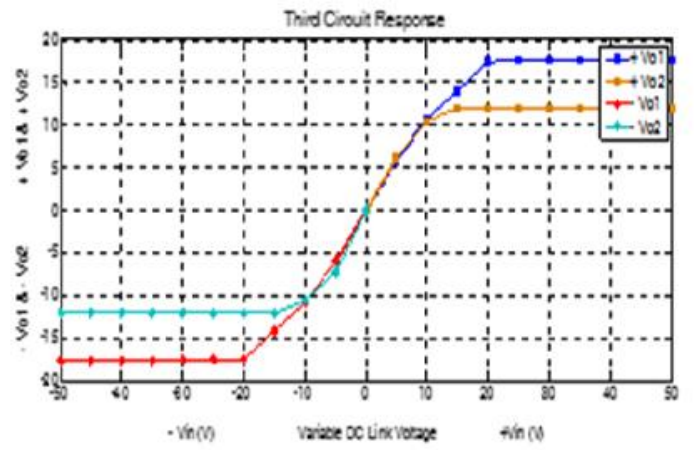

Fig. 9: $2^{\text {nd }}$ Regulator Circuit Response

\section{Sensing \& Protection Circuit}

This circuit works separately from the previous three circuits. The circuit senses the instantaneous value of the PV panel output voltage or the input variable DC supply voltage. It uses this input voltage as a supply through separate internal regulator then monitors the voltage value and compares it with a desired adjustable lower limit using general purpose operational amplifier (Op-Amp). The result of comparison decides the connection of the positive and negative levels supplying the PV system. The connection is controlled through relay contacts to protect the PV system under work from any weak supply voltage levels to the electronic circuits included in the system. Fig. 10 shows the electronic design of the sensing \& protection circuit. Table II shows all simulation results through a wide input $\mathrm{DC}$ voltage range $0 \mathrm{~V}$ to $50 \mathrm{~V}$. Fig. 11 shows the response for the circuit.

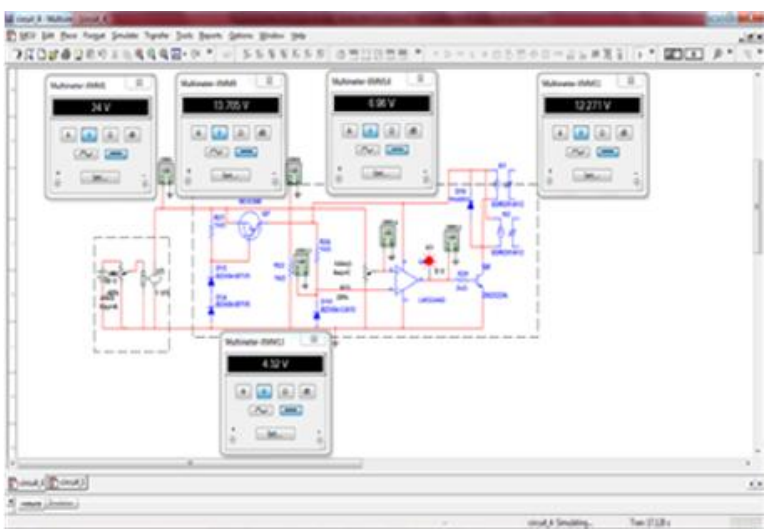

Fig. 10: Design of the Sensing \& Protection Circuit 
Table II Simulation Results at a Wide Input Voltage Range 0V to $50 \mathrm{~V}$

\begin{tabular}{|c|c|c|c|c|c|c|}
\hline $\begin{array}{l}\text { Vin } \\
\text { (V) }\end{array}$ & $\begin{array}{c}\mathrm{V} \\
\text { Sense } \\
(\mathrm{V})\end{array}$ & $\mathbf{Z}$ & $\begin{array}{l}\text { Vec } \\
(\mathrm{V})\end{array}$ & $\begin{array}{c}\text { Vzener } \\
\text { (V) }\end{array}$ & $\begin{array}{c}\text { Vout } \\
\text { (V) }\end{array}$ & $\begin{array}{l}\text { Relay } \\
\text { State }\end{array}$ \\
\hline 0 & 0 & & 0 & 0 & 0 & $0 / \mathrm{OFF}$ \\
\hline 5 & 1.45 & & 3.8 & 3.8 & 0 & $0 / \mathrm{OFF}$ \\
\hline 10 & 2.9 & & 8.74 & 4.3 & 0 & $0 / \mathrm{OFF}$ \\
\hline 14 & 4.06 & & 12.71 & 4.3 & 0 & $0 / \mathrm{OFF}$ \\
\hline 14.5 & 4.2 & & 13.21 & 4.3 & 0 & $0 / \mathrm{OFF}$ \\
\hline 15 & 4.35 & & 13.5 & 4.31 & 12.04 & $1 / \mathrm{ON}$ \\
\hline 20 & 5.8 & & 13.67 & 4.32 & 12.24 & $1 / \mathrm{ON}$ \\
\hline 25 & 7.25 & & 13.71 & 4.32 & 12.28 & $1 / \mathrm{ON}$ \\
\hline 30 & 8.7 & & 13.74 & 4.32 & 12.3 & $1 / \mathrm{ON}$ \\
\hline 35 & 10.15 & & 13.76 & 4.32 & 12.32 & $1 / \mathrm{ON}$ \\
\hline 40 & 11.6 & & 13.78 & 4.32 & 12.34 & $1 / \mathrm{ON}$ \\
\hline 45 & 13.05 & & 13.79 & 4.32 & 12.37 & $1 / \mathrm{ON}$ \\
\hline 50 & 14.5 & & 13.8 & 4.32 & 12.37 & $1 / \mathrm{ON}$ \\
\hline
\end{tabular}

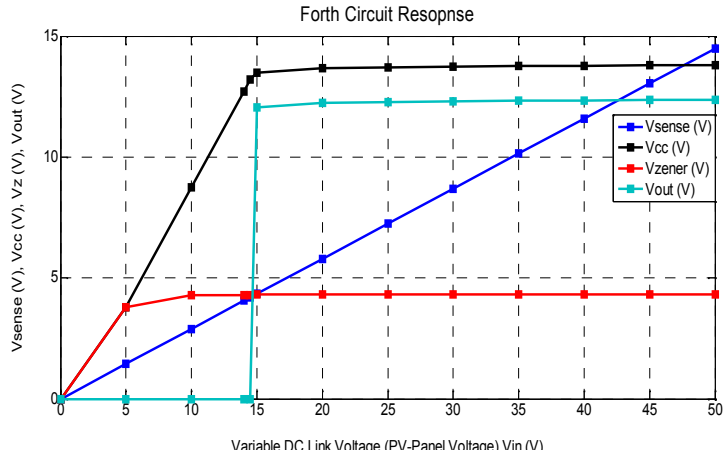

Fig. 11: Sensing \& Protection Circuit Response

\section{Conclusions}

This paper proposes an electronic design that can be used as DC power supply for PV systems. Solar energy could be effectively used as an alternative source of power for any PV system. All PV systems need suitable and stable DC power supply for proper functioning of the included electronic circuits. The presented work simulation results demonstrate the flexibility of modifying the input voltage range, the desired lower limit, and the values of the output positive and negative voltage regulators. There is an agreement between the proposed design and the simulation data showing the effectiveness of the proposed electronic design and promising for practical module. The proposed electronic design is based on general purpose discrete components, which simplifies the implementation with low cost manufacturing and maintenance procedures.

\section{References}

[1] J. Twidell, T. Weir, Renewable Energy Resources. $2^{\text {nd }}$ Ed., London \& New York:Taylor \& Francis, 2006.

[2] V. Devabhaktuni, M. Alam, S. R. Depuru, R. C. Green II, D. Nims, C. Near, "Solar energy: Trends and enabling technologies," Renewable and Sustainable Energy Reviews, Vol. 19, pp. 555$564,2013$.

[3] I. H. Altas and A. M. Sharaf, "A Photovoltaic Array Simulation Model for Matlab-Simulink GUI Environment," International Conference on Clean Electrical Power, ICCEP '07. 21-23 May 2007 , pp. $341-345$.

[4] H. A. Attia, B.N. Getu, H. Ghadban, A. K. Abu Mustafa, "Portable Solar Charger with Controlled Charging Current for Mobile Phone Devices," International Journal of Thermal \& Environmental Engineering, Vol. 7, No. 1, pp. 17-24, 2014.

[5] H. A. Attia, B.N. Getu, "Design \& Simulation of a Solar Tracking System for Optimum Energy Absorption," International Journal of Thermal \& Environmental Engineering, Vol. 8, No. 1, pp.1724,2014

[6] H. A. Attia, B. N. Getu, Y. I. Al-Mashhadany "Design and Simulation of Dual Axis Solar Tracker for Optimum Solar Energy Absorption," The International Conference on Electrical and Electronics Engineering, Clean Energy and Green Computing (EEECEGC2013), December 11-13, 2013, pp. 144-150.

[7] H. A. Attia, Y. I. Al-Mashhadany, B. N. Getu, "Design and Simulation of a High Performance Standalone Photovoltaic System," ICREGA'14-Renewable Energy: Generation and Applications, Springer Proceedings in Energy, 2014, pp 683-697.

[8] J. O. Oni, B. O. Bolaji, "Development of a universal DC power supply using solar photovoltaic, utility and battery power sources," Journal of Energy in Southern Africa, Vol 22 No 1, pp. 12-17, February 2011.

[9] A. E. Badoud and M. Khemliche, "Modeling, Design and Simulation of Stand-Alone Photovoltaic Power Systems with Battery Storage," Leonardo Journal of Sciences, Issue 22, pp. 123-142, January-June 2013.

[10] E. Koutroulis and K. Kalaitzakis, "Novel battery charging regulation system for photovoltaic applications," IEE Proc.-Electr. Power Appl., Vol. 151, No. 2, March 2004, pp. 191-197.

[11] S. Zadey, S. Dutt, "Design of converter for low power photovoltaic conversion system," International Journal of Advanced Research in Electrical, Electronics and Instrumentation Engineering Vol. 2, Issue 6, pp. 2733-2739, June 2013.

[12] W. Xiao, W. G. Dunford, P. R. Palmer and A. Capel, "Regulation of Photovoltaic Voltage," IEEE Transactions on Industrial Electronics, Vol. 54, No. 3, pp 1365-1374, June 2007.

[13] Y. I. Al-Mashhadany, H. A. Attia, "Novel Design and Implementation of Portable Charger through Low-Power PV Energy System," Advanced Materials Research, Vol. 925, pp. 495-499, Apr. 2014

[14] Y. I. Al-Mashhadany, H. A. Attia, "High performance for real portable charger through low power PV system," International Journal of Sustainable and Green Energy, 4(3-1): pp. 14-18, 2015 